\title{
Sexual inadequacy in the male
}

\author{
JOHN BANCROFT \\ M.D., M.R.C.P., D.P.M. \\ First Assistant, Department of Psychiatry, University of Oxford
}

\begin{abstract}
Summary
The adequacy of sexual functioning in the male depends on a complex interaction between psychological, hormonal and neurophysiological factors. Disturbance of any one of these factors may lead to sexual inadequacy. In the majority of cases no gross abnormality is found but the absence of gross hormonal or neurophysiological abnormality does not necessarily imply a purely psychological cause. Individual variations in the pattern of response of the autonomic nervous system or in the ability to learn control of autonomic responses such as erection or ejaculation may be sufficient to account for some cases of inadequacy and in others may increase the susceptibility to psychological factors. Further research is required to clarify these undoubtedly important psychophysiological relationships.

Treatment has been most successful when it has taken into account both psychological and physiological factors. The advances made by Masters \& Johnson (1970) in this area have partly depended on their earlier physiological and anatomical studies of sexual response (Masters \& Johnson, 1966).

It may be that in some cases the use of anxietyreducing drugs or androgens will be all that is required but further work is required to identify such cases. The placebo effects of such preparations should not be overlooked particularly as many cases of sexual inadequacy are based on lack of confidence or ignorance and require little more than good advice or reassurance.

Considerable advances in our understanding of these problems have been made in the past 20 years and techniques of endocrine, physiological and behavioural assessment are now available which should enable further progress to be made in the near future.
\end{abstract}

Sexual inadequacy is the failure to achieve satisfactory coitus. It is thus a problem affecting two people. The failure may lie with one partner more than the other but it is unusual for the responsibility to be entirely one-sided.

Having emphasized the 'dyadic' nature of sexual inadequacy, it is convenient to consider separately the ways in which each sex may be affected and this paper will confine itself to inadequate function in the male. The main types of such inadequacy will be described, their incidence and factors affecting theirw presentation to the physician considered, and pos $\frac{\Omega}{0}$ sible aetiological factors discussed. Finally method of treatment that are at present available and their reported results will be briefly reviewed.

The range of sexual inadequacy in the male

There are three aspects of a man's sexual pero formance which may be affected: the level of sexuab drive, erection and ejaculation.

\section{Low sexual drive}

Low sexual drive means a low level of sexwa arousability so that in the male sexual behavienr leading to coitus is less likely to be initiated. This is most likely to constitute a problem if a sexual partmer with a higher level of sexual drive is involved. Sexwab drive may be selectively lowered, e.g. the male whos has no sexual interest in his wife but does find otheo women stimulating, or may be generally lowered.

Such a person may simply complain of loss ob interest but be able to perform adequately if the sexual act is initiated by his partner. In others how 3 ever the loss of interest is combined with a degree of erectile or ejaculatory inadequacy. Low sexual drive. may be 'primary', i.e. present since puberty, ox 'secondary', i.e. developing after a period of relative normality.

\section{Erectile inadequacy or impotence}

This is the inability to produce or maintain an erection sufficient for satisfactory vaginal penetra tion and coitus. Erections may develop normall $P$ until vaginal penetration is either attempted of merely contemplated, when failure occurs. In othef cases the presence of a sexual partner will be sufficient to inhibit erection, though the man, wherp alone, can produce erections normally. Occasionally $y^{\prime}$ erections do not occur at any time, not even ore waking, but this is relatively rare.

Erectile impotence may be 'primary', i.e. erection sufficient for coitus has never been achieved, or 'secondary', i.e. at some stage in the past satisfactory coitus has occurred. 
Secondary impotence may be of 'acute onset', e.g. following some psychologically traumatic event, or of 'gradual onset', where it is associated with a gradual decline in sexual drive. Ejaculatory inadequacy is an important cause of secondary impotence, leading either to acute psychological trauma or when chronic to a more gradual onset of impotence.

\section{Ejaculatory inadequacy}

The commonest problem in this category is premature ejaculation. This has been arbitrarily defined by Masters \& Johnson (1970) as the inability to control ejaculation 'for a sufficient length of time during vaginal containment to satisfy the partner on at least $50 \%$ of their coital connections'.

As with erectile impotence, premature ejaculation can be 'primary' or 'secondary' although it is a problem that is usually at its worst early in a man's sexual career and is less often of late onset. It may however occur in certain sexual situations and not others.

The other problem in this category is ejaculatory incompetence. In this case ejaculation is either seriously delayed or does not occur at all during coitus. In the majority of cases ejaculation and orgasm are affected jointly. As with erectile impotence the problem may only arise during coitus, ejeculation occurring normally from other sources of penile stimulation such as mutual masturbation. In other cases the presence of a sexual partner is all that is required to ensure failure. Occasionally ejaculation only occurs during the sleeping state.

Ejaculatory incompetence may also be either 'primary' or 'secondary' and has to be distinguished from so-called 'dry-run' orgasm in which orgasm occurs but is not accompanied by ejaculation (Money \& Y ankowitz, 1967).

\section{Incidence of sexual inadequacy}

In the study of males reported by Kinsey, Pomeroy \& Martin (1948) the incidence of erectile impotence increased steadily with age. It had occurred in $1.3 \%$ of their population by the age of 35 . By the age of 50 the proportion was $6.7 \%$, by 60 it was $18.4 \%$ and by 75 it was $55 \%$. The proportion of these with primary impotence was apparently very small. In the older cases the impotence was usually associated with a decline in sexual interest. There are additional factors which determine whether sexual inadequacy is presented to the doctor and little is known of the incidence in clinical practice. The influence of the sexual partner is clearly important. If the female also experiences declining sexual interest then cessation of sexual activity may be accepted by both partners.
The role of the partner is particularly important in determining the incidence of premature ejaculation. According to Kinsey and his co-workers (Kinsey et al., 1948) approximately $75 \%$ of all males ejaculate within 2 min of vaginal entry and 'a not inconsiderable number of males' in less than $1 \mathrm{~min}$. A social class factor was involved however. Males in lower socio-economic groups would tend to ejaculate quickly and consider it the norm. Members of higher socio-economic groups were more inclined to delay ejaculation. The attitude of the female is clearly crucial. If women consider intercourse to be primarily a source of pleasure for the male, then rapid ejaculation will be accepted as normal by both partners. Such an attitude may have been more widespread in the past and may still be more frequent in the lower socio-economic groups. If the woman seeks orgasm herself then it becomes a problem if the ejaculation is too rapid for the woman to obtain satisfaction. Obviously the speed with which the woman reaches orgasm is an important variable also.

Ejaculatory incompetence is certainly less common than either erectile impotence or premature ejaculation. In Kinsey's series (Kinsey et al., 1948) it was reported in six of the 4108 cases. It is not clear from this report however whether this refers to absence of ejaculation and orgasm in the presence of a partner or total absence.

Sexual drive or 'appetite' is a difficult concept to define. The nearest one can get to measuring it in the male is to count the frequency of sexual outlets or orgasms. Clearly there are a number of factors which are likely to influence the level of such activity. The availability of an acceptable partner and culturally determined taboos on alternative methods of outlets such as masturbation are two examples. The high frequency may in some cases reflect a high level of concern about sexual performance rather than a high level of 'appetite'. If one allows for such factors however there is still evidence of considerable individual variation in the frequency of sexual outlet. In Kinsey's males (Kinsey et al., 1948) the mean frequency for all subjects was 2.74 outlets/week. For those under $31,2.9 \%$ showed a frequency of orgasm of once in 10 weeks or less. There was a steady increase in low-rating males after the age of 35 and age is obviously an important factor.

In the three main series of cases reported in the literature (Johnston, 1968; Cooper 1969a, b; Masters \& Johnson, 1970) erectile impotence is the commonest problem, ejaculatory incompetence the least common. Secondary impotence is considerably more frequent than the primary form. A complaint of low sexual drive is not usually made although certainly some patients do present in this way (Burnap \& Golden, 1967). 


\section{Possible aetiological factors in male sexual inadequacy}

In order to discuss aetiological factors the normal mechanisms underlying maintenance of sexual drive, erection and ejaculation will be briefly considered. These will be looked at in terms of endocrine, neurophysiological and psychological factors, with particular emphasis on the interaction between them.

\section{Sexual drive}

As with appetite for food, sexual drive reflects a complex interaction of psychological and physiological processes. The role of the central nervous system in this respect however is even less well understood than in the case of hunger. Evidence from ablation and depth-electrode studies in animals and the effects of localized pathology and cerebral surgery in man suggests that, as with other basic drives, the limbic system is involved, though the precise mechanisms remain unknown (Maclean, 1965). In the male the cerebral cortex is also involved, at least in the process of discriminating between sexual stimuli (Ford \& Beach, 1952).

The interaction of the endocrine system and central nervous system has been clearly demonstrated in the early development of gender differences in rodents and primates. The presence of androgens at critical stages of foetal development determines whether the brain thereafter behaves in a characteristically masculine or feminine way. This early sensitization also determines the later response to circulating androgens. If a female rat brain in utero is masculinized in this way, then later administration of testosterone will provoke characteristic masculine sexual behaviour (Harris, 1964). A similar effect has been demonstrated in primates (Goy, 1968).

Puberty is associated with an increase in circulating androgens due to the lessening of sensitivity of the hypothalamus to their inhibitory feed-back effect (Donovan, 1963). In the male, testosterone levels reach their maximum early in adolescence when sexual drive is probably at its height also. This may be partly due to the sensitizing effect that androgens have on erectile mechanisms leading to frequent erections (i.e. increased target organ sensitivity) and partly due to sensitization of the central nervous system to erotic stimuli.

Males who have gonadal failure or undergo castration before puberty are unlikely to experience any significant level of sexual drive. Castration or hypogonadism following puberty will result in marked reduction of sexual drive in the majority of cases but not all, and the reduction may be gradual over a year or more (Bremer, 1959). Replacement therapy with androgens will predictably restore sexual drive to its previous level in postpubertal hypogonadism or castration whilst its effects are less marked and less predictable in prepubertal cases (Money, 1961). This is consistent with experimental $\frac{7}{\mathbb{Q}}$ findings in cats (Lehrman, 1962). The late onset of $\propto$ puberty in humans is also associated with a relatively $\stackrel{.}{.}$ low sexual drive thereafter (Kinsey et al., 1948). $\overrightarrow{\overrightarrow{\vec{S}}}$

It thus seems possible that the establishment of $\frac{?}{0}$ normal adult levels of sexual drive depends on the $\frac{0}{\sigma}$ interaction between circulating androgens and be- $\overline{\bar{\rho}}$ haviour, and that this critical interaction takes place $\vec{\Phi}$ at the stage of puberty. Presumably in the normal $\frac{a}{\mathrm{v}}$ situation optimum hormonal and psychological (and ${ }^{\text {co }}$ hence behavioural) factors coincide, thus representing $\vec{\circ}$ a further 'critical period' of development.

Psychological factors clearly play a crucial part. $\bar{\omega}$ Sexual drive will be heightened by an erotic stimulus $\bar{C}$ whether external or internal (i.e. fantasy) and may 3 be inhibited by anxiety-provoking stimuli. How-i ever, if the necessary hormonal and metabolic state is not present purely psychological stimuli will be fr ineffective. That the interaction between sexual or behaviour and androgen levels is complex has been $\mathcal{N}$ further indicated by a recent finding that androgen 을 levels increase after sexual activity (Ismail \& Harkness, 1967). This means that low levels of androgens may be the result as well as the cause of low levels of sexual drive. There is probably considerable in $\$$ vidual variation in this respect; in some individuads $\vec{\omega}$ sexual abstinence appears to heighten sexual drive, in others it may be associated with reduction sexual drive. The explanation of such differences not yet understood.

Loss of sexual drive may be associated with a debilitating condition or starvation; it is a frequent $\frac{๊}{\varnothing}$ though not invariable accompaniment of depressive $\unrhd$ illnesses. The mechanism in such cases is not under- $\overrightarrow{\overrightarrow{0}}$ stood. Disorders of the temporal lobe are not in- 3 frequently associated with reduced sexual drive (Gastaut \& Collomb, 1954; Johnson, 1965; Hierons \& Saunders, 1966).

The role of endocrine dysfunction as a cause of lowered sexual drive also remains obscure. Heller \& $\overline{7}$ Myers (1944) described males with high levels of gonadotrophins in late adult life suggesting testicular failure. This syndrome they labelled the 'male

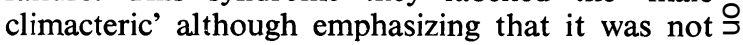
part of the normal aging process. Such men would $\frac{D}{2}$ report loss of libido which was correctable by testosterone therapy, in contrast to men with so- N called psychogenic impotence where gonadotrophin levels were normal and there was no response to androgens. Other reports of the relationship between $\omega$ androgen administration and the improvement in sexual drive or impotence were conflicting and $\stackrel{\varrho}{C}$ interest in the area was dropped mainly due to poor $\mathbb{\mathscr { N }}$ assay methods. With recent techniques however? interest has revived. A recent study of impotent males reported by Cooper et al. (1970) found low 
androgen levels in cases of so-called 'constitutional' impotence compared with normal levels in 'psychogenic' cases. The 'constitutional' cases were characterized by an insidious onset, with gradual loss of sexual drive starting relatively late in men whose sexual drive had never been particularly high. The aetiological distinction between 'constitutional' and 'psychogenic' requires justification however and as the authors point out the low androgen levels in the former group may have been the result rather than the cause of their lower levels of sexual outlet. In contrast to Heller \& Myers' 'male climacteric' group these 'constitutional' cases did not apparently benefit from exogenous androgens.

Administration of oestrogens to males is frequently associated with a reduction in sexual drive, an effect often made use of in the treatment of sexual offenders (Golla \& Hodge, 1949; Bierer \& Van Someren, 1950; Scott, 1964). The mechanism is not clear but may be due to an androgen-blocking effect of oestrogens. No systematic studies of such oestrogen effects have been carried out but it seems probable that in some it is sexual drive that is affected whilst in others sexual desire persists but erectile impotence prevails. Similar libido-reducing effects have been reported with the use of cyproterone, a specific anti-androgen (Laschet \& Laschet, 1968) and also with several tranquillizers, both phenothiazines (Bartholomew, 1968) and butyrophenones (Sterkmans \& Geertz, 1966). It is of interest that testosterone levels were found to be low in some patients on chlorpromazine studied by Ismail \& Harkness (1967).

\section{Penile erection and erectile impotence}

Erections are of two main types, 'reflexive' and 'psychic'. 'Reflexive' erections depend on lower spinal pathways only. Stimulation of the erotogenic zones is sufficient to produce such responses. The sensitivity of such pathways is controlled by inhibition from higher centres, as is demonstrated in spinal man when release from such inhibition results in a lowering of stimulus threshold.

Psychic erections depend on mediating processes in the central nervous system. They may occur in response to thoughts or fantasies or perceptions, particularly visual.

The neurological mechanisms involved in erection are not as straightforward as most physiology textbooks would have us believe. Reflexive erections are most probably mediated by cholinergic pathways but psychic erections may depend partly on adrenergic mechanisms also (Bancroft, 1970). The central pathways involved are not completely understood but MacLean \& Ploog (1962) have mapped out areas of the limbic system of the monkey, stimulation of which leads to erection.
The role of the endocrine system in erectile mechanisms is not clear though androgens probably increase sensitivity to both reflexive and psychic stimuli. This may account for the frequent occurrence of erections to non-specific stimuli in prepubertal boys when androgens are starting to rise (Ramsey, 1943). The effect of testosterone on psychic erections and sexual drive was clearly demonstrated in the case reported by Beumont et al. (1971).

The relationship between psychological factors and erection is obviously of crucial importance. The early over-simplified view that erection resulted from parasympathetic stimulation and was inhibited by sympathetic stimulation led to the view that anxiety inhibited erection by means of the autonomic arousal (or sympathetic activity) that accompanied it. There is evidence in both animals and man (Gantt, 1944; Ramsey, 1943; Bancroft, 1970) that erections may occur in situations which provoke anxiety. The presence of anxiety therefore does not necessarily mean the inhibition of erection. Recent work (Maclean \& Ploog, 1962; Bancroft \& Mathews, 1971) has also shown that erection is not necessarily accompanied by autonomic arousal and in some individuals may be accompanied by a lowering of autonomic arousal. Erection is therefore one of the autonomic responses that may occur following erotic stimulation. Whether it is accompanied by other autonomic changes, or by central arousal or subjective anxiety, and the pattern that these responses show, depends upon the characteristics of the situation and the response characteristics of the individual involved (Bancroft, 1971). There will thus be considerable variation between individuals. It remains a possibility that for some individuals the pattern of response will be fairly predictable from one occasion to the next (the concept of responsespecificity) whilst in others the pattern will vary according to the situation.

On this theoretical basis the relationship between anxiety and erection may be of at least four types. Firstly, anxiety and erection may co-exist; the individual approaches the situation in a way which leads to both anxiety and erection. Secondly, anxiety and the inhibition of erection may co-exist; appraisal of the situation leads to both direct inhibition of erection and anxiety. Thirdly, the presence of anxiety may interfere with the processes leading to erection, e.g. erection often follows the production of erotic fantasies and thoughts and anxiety may interfere with the production of such fantasies. (This mechanism should not affect 'reflexive' erections.) Finally there may be some individuals who require an optimum level of autonomic arousal for erections to occur; anxiety would tend to increase the arousal above its optimum level. 
The relationship is further complicated as the inhibition of erection may reduce anxiety by removing the threat of a sexual encounter or may increase the anxiety by causing a 'fear of failure'.

The psychological factors in the sexual situation which lead to either anxiety or inhibition of erection are very variable. Early experiences may lead to a fear of heterosexual relationship in general or more specifically those involving women that the man considers to be like his mother or 'respectable'. Such anxiety is thought by many psychoanalysts to stem from unresolved Oedipal problems though why it occurs in some men and not in others is not always clear. Other types of fears include phobias or feelings of disgust towards female genitalia, fears of pregnancy, or fears of venereal disease. Ignorance and the anxiety that it generates is a frequent problem as is sexual inhibition stemming from a childhood in which sexual expression has been suppressed and sex considered dirty. Sexual deviance such as homosexuality is frequently associated with fear of heterosexual relationships. In many cases the fear may have been an important factor contributing to the development of the deviant pattern. In others, however, the man, because of his deviant interest, considers himself to be innately abnormal or 'inverted' and hence incapable of normal heterosexual relationships. Such conviction will make him reluctant and fearful to attempt a heterosexual encounter.

A single episode of impotence due to such factors as alcoholic intoxication or some passing psychological trauma may initiate a continuing pattern of impotence, further sexual situations becoming threatening because of the possibility of failure. For many men impotence is one of the most traumatic types of failure they can experience.

The tendency to inhibit erections is a characteristic which appears to make some individuals particularly vulnerable to the effect of such sexual 'threats'. The severity of the impotence therefore is not necessarily an indication of the severity of the psychological problem or threat leading to it. Most writers have assumed in the past that impotence is a symptom of a neurotic personality and sexual inadequacy has been shown to be common amongst neurotic individuals (Slater, 1945). The proportion of sexually inadequate males who have neurotic personalities has varied in different reports (El-Senoussi, Coleman \& Tauber, 1959; Cooper, 1968). Certainly in some the neurosis is as much a result of the sexual problem as a cause, particularly when the sexual inadequacy has been of early onset. On the other hand some men cope with considerable psychological difficulties and sexual traumas without impotence adding to their troubles. What then is the nature of such psychophysiological vulnerability? This important question remains to be answered with certainty. ‡ Erection, however, is a response which can be sub- $\frac{3}{8}$ jected to an unusual amount of control compared $\stackrel{\mathbb{D}}{\square}$ with other autonomic responses (Laws \& Rubin, $\stackrel{\hookrightarrow}{\hookrightarrow}$ 1969). This control may depend on a subtle inter- $\overrightarrow{\vec{A}}$ action between awareness or 'feed-back' of erection $\overrightarrow{0}$ and the cognitive processes that precede it, awareness $\frac{}{0}$ of slight increases in erections serving to inform the $\overline{\bar{c}}$ subject that his cognitive processes are being effec- $\overparen{\nabla}$ tive. In general, control of autonomic responses such as heart rate or blood pressure can be learnt when ${ }^{\text {कs }}$ such 'feed-back' is available but such learning is $\vec{O}$ fairly subtle (Bremer, Kleinman \& Goesling, 1969; $\overrightarrow{\dot{\omega}}$ Shapiro et al., 1969). In learning control of erections the process may possibly 'go wrong' if too much attention is paid to 'feed-back'; the subject becoming 3 preoccupied with his degree of erection thus interfering with rather than facilitating the cognitive processes leading to erection. Certainly it is an im- $y$ portant feature in the treatment of erectile impo- or tence to direct attention away from the erectile $N$ process (Masters \& Johnson, 1970).

\section{Emission and ejaculation}

Emission of semen results from contraction of theco smooth muscles of the vas deferens, mediated by the sympathetic nervous system. Ejaculation then resulfs $\vec{\omega}$ from rhythmic contractions of the ischio and bulber cavernosus muscles leading to spurts of semę: This is mediated by cholinergic fibres of the part sympathetic sacral outflow. Emission can occur without ejaculation. Emission and ejaculation are $\bar{\partial}$ normally accompanied by orgasm in which variable $\stackrel{\mathscr{Q}}{\mathbb{Q}}$

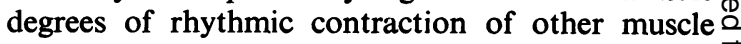
groups may occur.

Ismail \& Harkness (1967) have suggested a mechanism by which emission may serve to maintain normal levels of androgens. The importance of androgens in facilitating orgasm and emission is less $\bar{\partial}$ certain, however. The neurophysiological mechanisms underlying orgasm are not understood and $\frac{5}{3}$ central pathways have not been clearly demonstrated. At the spinal level, however, the degree of excitation in the spinal centres presumably reaches a threshold beyond which there is a spread of activity or dis- 을 charge through the sympathetic fibres resulting in $\frac{D}{0}$ emission. A spread of excitation through the spinal pathways may result in the climax of sensation and $N$ muscular activity which can either generalize very $N$ widely through the body or be localized. The re- $N$ lationship between the level of autonomic arousal $\omega$ and the production of orgasm remains uncertain. It seems probable, however, that a state of high arousal, whether due to excitement or anxiety, faci- $\mathbb{D}$ litates the emission process.

It is therefore more likely that the physiological $\frac{T}{0}$ states accompanying anxiety directly influence 
emission rather than erection. Sexual excitement will have a similar effect except that the orgasm resulting will be more intense and pleasurable. The ability to delay or control emission and ejaculation tends to increase with age. This is partly due to a reduction in novelty of the sexual partner so that less excitement is generated, but also some learning of control apparently takes place (Johnson, 1968). Premature ejaculation may therefore be due either to anxiety (regardless of the origins of that anxiety) or excitement. Or, alternatively it may result from failure to learn control of ejaculation. As with erectile impotence, anxiety can occur as a consequence of 'fear of failure' so that a vicious circle can arise, and in fact secondary erectile impotence may also develop later.

In cases of ejaculatory incompetence erections occur readily but in spite of normally adequate stimulation orgasm and ejaculation do not. It seems likely that psychological factors may play a more direct role in these cases than in the case of premature ejaculation (Masters \& Johnson, 1970). Extreme religious orthodoxy, marked sexual inhibitions or some traumatic sexual incident are commonly found in such cases. The mechanism here is, therefore, comparable with erectile impotence in that specific inhibition occurs, but, in this case, of the orgasmic and ejaculatory rather than the erectile mechanisms. This inhibition may be part of the general inability to 'let oneself go' or to become sufficiently abandoned sexually to reach the threshold of sexual excitation necessary for orgasm and ejaculation to occur, or it may stem from a more specific need to avoid ejaculation itself.

\section{Treatment of sexual inadequacy in the male}

In a person complaining of sexual inadequacy, the possibility of a physical or psychiatric illness being the cause must be considered, as obviously this will determine the appropriate treatment. In all but a few cases, however, no such cause will be found. The possibility that the sexual problem is being used as a scapegoat for other difficulties, especially marital ones, should also be considered. If this appears to be the case, then treatment directed at the sexual problem is unlikely to be helpful. Only after adequate initial assessment should treatment therefore be started.

Earlier methods of treatment have been reviewed by Johnson (1968). At the present time treatment can be considered under three headings: (a) drugs; (b) hormones; and (c) psychological methods.

\section{Drug treatment}

Two types of drug treatment have been advocated, firstly the use of anti-anxiety drugs, and secondly the use of drugs to delay ejaculation. In the first case the purpose is to reduce anxiety which as a physiological state is assumed to inhibit performance. The argument against this rationale in the case of erectile impotence has been put forward above, the evidence suggesting that in many cases it is not anxiety per se but specific inhibition of erection that is responsible. In the author's experience such drugs are only occasionally of value and so far there has been no systematic evaluation of their use.

The rationale for the use of anti-anxiety drugs in the treatment of premature ejaculation is easier to justify. Schapiro (1943) classified premature ejaculation cases into those associated with high arousal due to high anxiety or excitement, and those without high arousal. In the former group he reported success with the use of sedatives. Once again, however, no systematic study has been carried out and the precise value of such drugs remains uncertain. The side-effects of some adrenergic blocking drugs such as mono-amine oxidase inhibitors or phenothiazines in occasionally interfering with ejaculation in otherwise sexually adequate males has led some workers to recommend their use in treating premature ejaculation (Bennet, 1961). However, considering the hazards and side-effects of such drugs it is not yet possible to justify their use for this purpose.

At the present time, therefore, there is no certain evidence of the value of drugs in the treatment of male sexual inadequacy.

\section{Hormonal treatment}

The effects of male hormones on sexual inadequacy have already been referred to (Heller \& Myers, 1944; Cooper et al., 1970). Johnson (1968) reported twelve cases treated with testosterone and two improved. Success has been claimed for a mixture containing methyltestosterone, yohimbine, pemoline and strychnine. Its superiority to placebo was reported in a double-blind study of forty-one cases (Bruhl \& Leslie, 1963). A further 2000 cases were reported with a substantial improvement rate (Margolis et al., 1967). Neither of these reports is convincing but they do suggest a possible effect which should be more closely studied. At the moment, therefore, the use of androgens in treating sexual inadequacy is also uncertain and little is known of the hazards of longterm medication in such cases.

\section{Psychological treatment}

Methods of psychological treatment have ranged from full psychoanalysis to simple counselling or reassurance.

In Johnson's series (1968), seventy-five cases were followed up. Of these twenty-three $(38 \%)$ refused or were not offered treatment. Of this untreated group six $(26 \%)$ were improved at follow-up. Of the fortytwo treated patients seventeen $(40 \%)$ were improved 
or 'cured'. Various types of treatment were involved, however. Nineteen patients received some physical or drug treatment (e.g. testosterone, ECT, or circumcision). Four $(21 \%)$ of this group improved. The remaining twenty-three were treated by various psychological methods. Of these thirteen $(57 \%)$ were improved or cured. The psychological methods therefore produced the best results, and of these methods joint marital counselling appeared to be most successful (of four couples treated in this way two were improved, two cured). The numbers receiving each method were too small, however, to draw any firm conclusions. The best results were with secondary erectile impotence, primary disorders responding generally less well and premature ejaculation responding poorly.

In Cooper's (1969a) series of fifty-seven patients with erectile impotence or ejaculatory incompetence, forty-nine were treated. Of these nineteen $(39 \%)$ were recovered or improved at follow-up. The best results were in those with acute onset of erectile impotence; $88 \%$ of these did well. Of the cases of erectile impotence with an insidious onset, usually at a later age, only $26 \%$ did well. Forty-six per cent of the cases of ejaculatory incompetence improved. In a further thirty cases of premature ejaculation (Cooper 1969b) 43\% were improved, the best results being in the 'acute onset' cases.

Cooper's method consisted of a combination of relaxation training (in order that the patient could learn to relax during sexual stimulation), advice on producing optimum sexual stimulation from the partner, sexual education for both partners, and superficial psychotherapy.

Apart from the obviously superior outcome of the cases of acute onset, other variables which were associated with a favourable response were youth, duration of the disorder less than 2 years, a 'secondary disorder', heterosexual orientation, 'normal' personality, and co-operation of the female partner in treatment.

Wolpe \& Lazarus (1966) report the results of treatment in thirty-one cases of male sexual inadequacy. Unfortunately they did not give details of the type of disorder involved. Twenty-one patients $(67 \cdot 7 \%)$ achieved entirely satisfactory sexual performance and a further six $(19.4 \%)$ were improved.

The rationale of their method was that sexual inadequacy resulted from anxiety in the sexual situation and treatment, therefore, should aim at reducing the anxiety. In most cases Wolpe's principle of reciprocal inhibition of anxiety was involved though not by means of muscular relaxation but by using the presumed anxiety-inhibiting effect of sexual arousal. Thus the patient and his partner would be instructed to indulge in sexual contact only as long as he was free from anxiety. Coitus was advised against in the early stages. By this mean⿳⺈ sexual arousal increased and permitted contac nearer and nearer to coitus. The patient was also advised on alternative ways of satisfying his partner. They emphasised the importance of the partner $\overrightarrow{\bar{F}}$ co-operation though they would not necessarily intero view her themselves. Occasionally they found tha the patient was so frightened of women that eve $\overline{\bar{p}}$. being alone in their presence would provoke anxiety In such cases they would use systematic desensitiza tion of imaginary sexual situations in the same way as is used for treating phobias (Wolpe, 1958).

Friedman (1968) treated nineteen cases with systematic desensitization in this way, except that intravenous barbiturate was used as the antis anxiety agent rather than muscular relaxation. Eight out of ten cases with erectile impotence wera cured; three out of six with premature ejaculation were cured; and three cases of ejaculatory incoms petence failed to respond.

The most impressive series, in results, numbers treated and technique is that reported by MasterQ and Johnson (1970). The results are shown in Table 1.

\section{TABLE 1.}

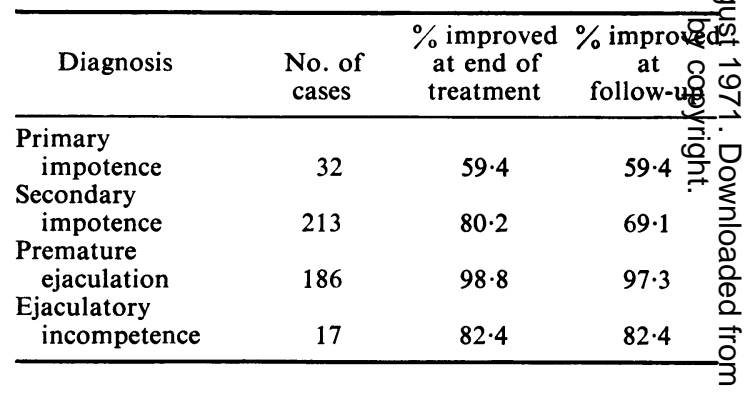

The long-term stability of these results, which are based on a 5-year follow-up, is shown in all group? except secondary impotence. These results are generally superior, therefore, to those of other series but particularly in the case of premature ejaculation $\frac{5}{3}$ With the exception of Tuthill (1955) most workers have reported poor results with premature ejacula tion (Hastings, 1963).

The treatment method of Masters \& Johnson (1970) deserves closer attention, although for those readers wanting to apply their techniques reference

to the full report is essential.
Patients in their study were treated for a set period of 2 weeks. During this time they stayed in a nearby hotel attending the treatment centre each day. They were thus a highly motivated group and predomi? nantly middle class. Some attempt to screen the patients before accepting referral was made, in particular to exclude psychotic illness.

Masters \& Johnson stressed the necessity of con $\frac{T}{0}$ joint therapy, so much so that if males sought treat 
ment without a partner, surrogate partners were supplied. In addition, they used a male and female therapist in each case whose qualifications and training were such that all aspects of treatment including physical examination and investigation could be carried out by them.

The first 4 or 5 days of treatment were the same whatever the problem. The couple were told at the start to avoid any sexual contact until instructed otherwise. The sessions on the first 2 days were spent in history-taking, each partner separately with the same sexed therapist. History-taking was thorough enough to give the therapist a clear idea of the individual's 'sexual value system'-what his sexual attitudes were and what he accepted as normal or desirable, in addition to a detailed account of past sexual experiences and present difficulties.

On the third day there was a 'round table discussion' with both patients and both therapists involved. This was used to explain to each partner the anxieties and difficulties of the other, to emphasize that 'fears of performance' act both in the female and male to block the reception of erotic stimuli in the sexual situation. Communication between the married pair, both verbally and later physically was strongly encouraged. The 'spectator role' that sexually inadequate individuals adopt was also discouraged; neither the male nor the female observing what is going on during the sexual act can fully respond to the erotic stimuli in the situation. On the third and fourth day the couple were instructed to concentrate on 'sensate focus' which means exploring each other's bodies to discover areas and methods of tactile stimulation that are pleasurable. On the second of these days the genital areas were included in this exploration, but throughout it was made very explicit that the release of sexual tension through orgasm was not being sought. In many of their patients their abilities to respond to such stimulation had been largely overshadowed by their preoccupation with performance and orgasmic release.

From the sixth day onwards, direction from the therapist was specifically related to the type of sexual inadequacy involved. In the case of erectile impotence, attention was directed away from the erectile process until erections occurred spontaneously The pair were then encouraged to permit the erection to come and go, thus demonstrating that the loss of erection is not irrevocable. This is an important psychological step. Following this the partner was instructed in intermittent vaginal insertion adopting the superior coital position, until erection was maintained.

In treatment of premature ejaculation the partner was instructed in penile stimulation just short of ejaculation at which point the penis was squeezed strongly between finger and thumb. This procedure was carried out repeatedly and eventually manual stimulation gave way to intermittent vaginal entry again with the woman in the superior coital position. The 'squeeze' technique was continued, however, for several months until finally ejaculation could be avoided without it. This technique has some similarities to the method described by Semans (1956) for the treatment of premature ejaculation, although in the latter case no squeezing was involved. Semans' method, however, has never been systematically evaluated.

In the case of ejaculatory incompetence emphasis was on vigorous penile stimulation by the partner with the aid of a lubricating jelly. Once ejaculation occurred with manual stimulation, the woman, again in the superior coital position, stimulated her partner to ejaculate, inserting the penis into the vagina before ejaculation occurred. Once ejaculation has occurred into the vagina an important psychological barrier is overcome and and thereafter the level of inhibition appears to be lower so that vigorous stimulation becomes less necessary.

Masters \& Johnson found that undue religious orthodoxy and homosexual propensity both carried a poor prognosis, regardless of the type of inadequacy.

Although the above techniques involve several of the features of earlier methods, it must be concluded that at the present time Masters \& Johnson have evolved the most successful approach to the treatment of sexual inadequacy. This combines the assessment and modification of relevant sexual attitudes with directive counselling in sexual technique. Unfortunately their full method is relatively impracticable within the National Health Service, but when their findings are considered together with those of other workers, various points can be made which are of practical relevance to treatment.

Treatment is most likely to be successful when (1) both members of the marital unit or pair are prepared to take part in treatment and each one accepts that he or she is involved in the problem. Ideally they should be prepared to leave their normal routines for a short period. (2) The problem is of recent onset. (3) Satisfactory sexual performance has occurred in the past (i.e. the inadequacy is secondary). (4) The problem has developed 'acutely' rather than slowly with a gradual loss of sexual interest. (5) There is no severe personality problem, undue religious orthodoxy or homosexual propensity in either partner.

The following points are of value in carrying out treatment.

(1) A specified number of treatment sessions is stated at the onset. The patients then know what to expect and improvement is more likely to occur in 
the time available. For those cases who are likely to improve, ten to fifteen sessions should be sufficient.

(2) Sessions should be close together so that patients can discuss difficulties as they arise. Once a week is the most practical. The extent to which the couple are prepared to organize their lives to fit in with the needs of treatment is a good indication of their motivation.

(3) Equal attention is paid to both partnersso there is no one patient. Full histories should be taken from both, regardless of who has the presenting problem.

(4) Clear instructions are given to the pair at the start to avoid intercourse or any attempt to achieve orgasm until instructed otherwise. It is helpful to give these instructions to the pair jointly.

(5) A careful search for any ignorance or misunderstanding of sexual matters is made in both partners and the necessary information provided to correct it.

(6) Attention is paid to encouraging and facilitating communication between the partners about sexual responses and feelings.

(7) Instructions are given to concentrate on enjoying mutual erotic stimulation with no orgasmic release. The natural occurrence of erections and orgasm when the individual permits erotic stimuli to act is explained and the futility of trying to force these responses is stressed.

(8) Instructions relevant to the specific problem are given according to the methods of Masters \& Johnson (1970). It is important that such techniques are discussed in considerable detail so that the therapist feels confident that he knows what is taking place. It is easy to be misled by the glossing over of embarrassing details and it should, in any case, be an important aim of treatment that such details can be discussed without embarrassment.

\section{References}

BANCROFT, J.H.J. (1970) Disorders of sexual potency. In: Modern Trends in Psychosomatic Medicine (Ed. by O. W. Hill). Butterworth, London.

BANCROFT, J.H.J. (1971) The application of psychophysiological measures to the assessment and modification of sexual behaviour. Behaviour Research and Therapy, 9, 119.

BANCroft, J.H.J. \& Mathews, A. (1971) Autonomic correlates of penile erection. Journal of Psychosomatic Research, 15, 159.

BARTholomew, A.A. (1968) A long-acting phenothiazine as a possible agent to control deviant sexual behaviour. American Journal of Psychiatry, 124, 917.

BeNNET, D. (1961) Treatment of ejaculatio praecox with monoamine oxidase inhibitors. Lancet, ii, 1309.

Beumont, P.J.V., Bancroft, J.H.J., Beardwood, C.J. \& RuSSELl, G.F.M. (1971) Behavioural changes following treatment with testosterone: a case report. Psychological Medicine. (In press.)

Bierer, J. \& VAN Someren, G.A. (1950) Stilboestrol in outpatient treatment of sexual offenders. British Medical Journal, 1, 935.
Bremer, J. (1959) Asexualization. MacMillan, New York.

Bremer, J. Kleinman, R.A. \& Goesling, W.J. (1969) The $\bar{\gamma}$ effects of different exposures to augmented sensory feed- $\$$ back on the control of heart rate. Psychophysiology, $5,510 . c$

BRuHL, E.E. \& Leslie, C.H. (1963) Afrodex, double blind:test in impotence. Medical Record and Annals, 56, 22.

BurNaP, D.W. \& Golden, J.S. (1967) Sexual problems in medical practice. Journal of Medical Education, 42, 673.

COOPER, A.J. (1968) 'Neurosis' and disorders of sexual 음 potency in the male. Journal of Psychosomatic Research, 12, 141 .

COOPER, A.J. (1969a) Outpatient treatment of impotence. Journal of Nervous and Mental Disease, 149, 360.

COOPER, A.J. (1969b) Clinical and therapeutic studies in $\vec{\circ}$ premature ejaculation. Comprehensive Psychiatry, 10, 285.

Cooper, A.J., Ismail, A.A.A., Smith, C.G. \& Loraine, J.A. $\vec{\omega}$ (1970) Androgen function in 'psychogenic' and 'constitutional' types of impotence. British Medical Journal, 37 17.

Donovan, B.T. (1963) The timing of puberty. Scientific. Basis of Medicine Annual Review, 53.

El-Senoussi, A., Coleman, D.R. \& Tauber, A.S. (1959)نَ Factors in male impotence. Journal of Psychology, 48, 3.

FORD, C.S. \& BEACH, F.A. (1952) Patterns of Sexual Be-cir haviour. Eyre and Spottiswoode, London.

Friedman, D. (1968) The treatment of impotence by Brietal relaxation therapy. Behaviour Research and Therapy, 6, $\supset$ 257.

GANTT, H. (1944) The Experimental Basis of Neurotic Behaviour. Hoeber, New York.

Gastaut, H. \& Collomb, J. (1954) Etude du comportementos sexual chez les Epileptiques Psychomoteurs. Annales médico-psychologiques, 112, 657.

Golla, F.L. \& Hodge, S.R. (1949) Hormone treatment $\mathrm{g} f-$ the sex offender. Lancet, i, 1006.

GoY, R.N. (1968) Organising effects of androgens on the behaviour of Rhesus monkeys. In: Endocrinology and Behaviour (Ed. by R. P. Michael). Oxford University Press, $\overline{0}$ Oxford.

HaRRIS, G.W. (1964) Sex hormones, brain development and $\mathbb{D}$ brain functions. Endocrinology, 75, 627.

Hastings, D.W. (1963) Impotence and Frigidity. Churchill, $\overline{\mathrm{O}}$ London.

Heller, C.G. \& Myers, G.B. (1944) The male climacteric: its symptomatology, diagnosis and treatment. Journal of the American Medical Association, 126, 472.

Hierons, R. \& SAUnders, M. (1966) Impotence in patients with temporal lobe lesions. Lancet, ii, 761.

IsmaIL, A.A.A. \& HARKNESS, R.A. (1967) Urinary testosterone excretion in men in normal and pathological conditions. Acta Endocrinologica, 56, 469.

Kinsey, A.C., Pomeroy, W.B. \& Martin, C.E. (1948) Sexual Behaviour in the Human Male. Saunders, London. 0

Kinsey, A.C., Pomeroy, W.B., Martin, C.E. \& Gebhard, P.H. (1953) Sexual Behaviour in the Human Female. $\frac{T}{0}$ Saunders, London.

JoHnSON, J. (1965) Sexual impotence and the limbic system. N British Journal of Psychiatry, 111, 300.

Johnson, J. (1968) Disorders of Sexual Potency in the Male. N Pergamon Press, Oxford.

LASCHET, U. \& LASCHET, L. (1968) The treatment of patho- $\omega$ logically increased and degenerative sexuality of man with the anti-androgen cyproterone acetate. In: Das Testo- 6 steron-Die Struma (Ed. by E. Klein). Springer-Verlag, Berlin.

LAws, D.R. \& RuBin, H.B. (1969) Instructional control of $T$ an autonomic sexual response. Journal of Applied Behavioural Science, 2, 93. 
LEHRMAN (1962) Interaction of hormonal and experiential influences on development of behaviour. In: Roots of Behaviour (Ed. by E. L. Bliss). Harper and Row, London.

MACLEAN, P.D. (1965) New findings relevant to the evolution of psychosexual functions of the brain. In: Sex Research: New Developments (Ed. by J. Money). Holt, Rinehart and Winston, New York.

Maclean, P.D. \& Ploog, D.W. (1962) Cerebral representation of penile erection. Journal of Neurophysiology, 25, 29.

Margolis, R., Sangree, H., Prieto, P., Stein, L. \& Chinn, S. (1967) Clinical studies of the use of Afrodex in the treatment of impotence. Current Therapeutic Research, Clinical and Experimental, 9, 213.

Masters, W.J. \& Johnson, V.E. (1966) Human Sexual Response. Churchill, London.

MAsters, W.H. \& Johnson, V.E. (1970) Human Sexual Inadequacy. Churchill, London.

MoNey, J. (1961) Sex hormones and other variables in human eroticism. In: Sex and Internal Secretions (Ed. by W. X. Young), 3rd edn. Williams and Williams, Baltimore.

Money, J. \& Yankowitz, R. (1967) The sympathetic inhibiting effects of the drug Ismelin on human male eroticism with a note on Melleril. Journal of Sex Research, 3, 69.
Ramsey, G.V. (1943) The sexual development of boys. American Journal of Psychology, 56, 217.

Schapiro, B. (1943) Premature ejaculation. A review of 1130 cases. Journal of Urology, 50, 374.

ScotT, P.D. (1964) Definition classification prognosis and treatment. In: The Pathology and Treatment of Sexual Deviation (Ed. by I. Rosen). Oxford University Press, Oxford.

Semans, J.H. (1956) Premature ejaculation: a new approach. Journal of Urology, 49, 353.

Shapiro, D., Tursky, B., Gershon, E. \& Stern, M. (1969) Effects of feedback and reinforcement on the control of human systolic blood pressure. Science, 163, 588.

SLATER, E. (1945) Neurosis and sexuality. Journal of Neurology, Neurosurgery and Psychiatry, 8, 12.

Sterkmans, P. \& Geerts, F. (1966) Is Benperidol (R4584) the specific drug for the treatment of excessive disinhibited sexual behaviour? Acta neurologica et psychiatrica Belgica, 66, 1030 .

TUtHiLl, J.F. (1955) Impotence. Lancet, i, 124.

WOLPE, J. (1958) Psychotherapy by Reciprocal Inhibition. Stanford University Press, California.

Wolpe, J. \& LAZARUS, A.A. (1966) Behaviour Therapy Techniques. Pergamon Press, Oxford. 